\title{
Unidades possíveis para uma obutchénie dialética e desenvolvedora ${ }^{1}$.
}

DOI 10.26512/Ic.v24i0.19815

Andréa Maturano Longarezi

Universidade Federal de Uberlândia

Walêska Dayse Dias de Sousa

Universidade Federal do Triângulo Mineiro

\section{Resumo}

O artigo discute uma concepção de "Obutchénie por Unidades" como proposição para uma didática dialética, no contexto da educação pública brasileira. Como aporte teórico o trabalho fundamenta-se na Psicologia Histórico-Cultural, na Teoria da Atividade e na Didática Desenvolvimental. O texto problematiza unidades possíveis para uma obutchénie desenvolvedora, a partir de intervenções didático-formativas realizadas por pesquisadores do Gepedi. Da unidade primária "ensino-aprendizagem" (obutchénie) e da unidade obutchénie-desenvolvimento, propõem-se como fundamentos orientadores da organização didática as unidades conteúdo-forma, imitação-criação e ruptura-desenvolvimento.

Palavras-chave: Ensino Desenvolvimental. Obutchénie-desenvolvimento. Obutchénie por Unidades. Educação Pública Brasileira. Educação Dialética.

1 O artigo apresenta proposições, cujas análises têm suas origens no contexto de projetos de pesquisa financiados pela Fapemig, CNPq e Capes. Os projetos que deram origem à pesquisa (Longarezi, 2012, 2014, Longarezi, 2017a) articulam vários subprojetos de doutorado (Franco, 2015; Dias de Sousa, 2016; Germanos, 2016; Coelho, 2016; Souza, 2017; Ferreira, 2017; Marra, 2017; Jesus, 2018), mestrado (Souza, 2016; Ferola, 2017) e iniciação científica (Ferola, 2016; Gali, 2018). As pesquisas vêm sendo desenvolvidas, portanto, por pesquisadores vinculados ao Gepedi, da UFU, que têm se dedicado a investigações com intervenções didáticas no Brasil, numa perspectiva que se tem (Puentes e Longarezi, 2017) chamado de histórico-cultural da atividade. 


\section{Abstract}

The article discusses an "Obutchénie by Units" conception as a proposition for a dialectic didactic, in the context of Brazilian public education. As a theoretical contribution, the work is based on Historical-Cultural Psychology, on Activity Theory and on Developmental Didactic. The text aims to problematize some possible units for a developer obutchénie, from didactic-formative approaches carried out by Gepedi researchers. From the primary unit "teaching-learning" (obutchénie) and obutchéniedevelopment unit content-form, imitation-creation and rupture-development units are proposed as guiding principles of the didactic organization.

Keywords: Developmental Teaching. Obutchénie-development. Obutchénie by Units. Brazilian Public Education. Dialectical Education.

\section{Résumé}

Cet article met en discussion la conception de "Obutchénie par Unités" en tant que proposition pour la didactique dialectique, dans le cadre de l'éducation publique brésilienne. Étant une contribution théorique, le travail est basé sur la psychologie historico-culturelle, la théorie de l'activité et sur la didactique du développement. Le texte entrentient une problématisation d'unités possibles pour une obutchénie développeur, à partir des interventions didactico-formatives mises en practique par les chercheurs du Gepedi. Partant de l'unité originaire "enseignement-apprentissage" (obutchénie) t de l'unité obutchenie-développement, sont proposés comme principes directeurs de l'organisation didactique des une forme-contenu, une imitationcréation, des unités de rupture-développement.

Mots-clés: Enseignement visant le développement; Obutchénie-développement. Obutchénie par Unités. L'éducation Publique Brésilienne. L'éducation Didactique 


\section{Resumen}

El artículo discute una concepción de "Obutchénie por Unidades" como proposición para una didáctica dialéctica, en el contexto de la educación pública brasileña. Como aporte teórico el trabajo se fundamenta en la Psicología Histórico-Cultural, en la Teoría de la Actividad y en la Didáctica Desarrolladora. El texto problematiza unidades posibles para una obutchénie desenvolvedora, a partir de intervenciones didáctico-formativas realizadas por investigadores del Gepedi. De la unidad primaria "enseñanza-aprendizaje" (obutchénie) y de la unidad obutchénie-desarrollo, se proponen como fundamentos orientadores de la organización didáctica las unidades contenido-forma, imitación-creación, ruptura-desarrollo.

Palabras-clave: Enseñanza Desarrolladora. Obutchénie-desarrollado. Obutchénie por Unidades. Educación Pública Brasileña. Educación dialéctica.

\section{Palavras introdutórias: o descortinar de uma perspectiva}

Longe de se fazer qualquer tipo de apologia, toma-se como horizonte uma proposta de obutchénie que se materialize como unidade dos contrários. (Longarezi, 2017b, p. 189).

Uma proposta de didática que reconhece a maneira peculiar com que o homem produz sua humanidade numa concepção histórico-cultural, na qual o humano individual e o social se produzem reciprocamente, na trama das particularidades e generalidades do homem e da cultura, não pode se concretizar de maneira linear, desconsideradas as condições objetivo-subjetivas dessa produção. Assim, a despeito do enorme desafio que se constitui para a área da educação delinear/propor/ discutir o campo da didática e do didático em torno às contradições que permeiam as relações de professores e estudantes em contextos concretos, assume-se essa necessidade. A produção desse tipo de didática se faz em meios reais à existência humana, sob a base da unidade contraditória, do movimento permanente do mundo, do confronto de pensamentos-emoções como o nuclear das forças mobilizadoras do desenvolvimento.

Nesse universo, propõe-se a compreensão de uma didática que se constitua dialética e desenvolvedora do homem e da sociedade, alicerçada sob as forças contraditórias da existência humano-cultural que se efetivam "como unidade" e "por unidades". Tal problemática emerge a partir de um intenso processo de investigação com intervenções 
didático-formativas ${ }^{2}$, produzidas por alguns pesquisadores do Gepedi - Grupo de Estudos e Pesquisas em Didática Desenvolvimental e Profissionalização Docente -, em contextos escolares distintos, da Educação Básica ao Ensino Superior. Essa experiência brasileira de produzir uma didática desenvolvedora, com base nos fundamentos da Teoria Histórico-Cutural, em Vigotski; da Teoria da Atividade, em Leontiev; e do Ensino Desenvolvimental, em Elkonin-Davidov, Galperin-Talízina, Zankov e seus vários grupos de pesquisa, tem notadamente revelado aspectos importantes para a constituição de uma perspectiva didática que seja desenvolvedora do estudante e do professor nas condições subjetivas e objetivas que caracterizam a realidade brasileira na atualidade.

Nesse contexto investigativo, emerge, portanto, a proposta de uma "Obutchénie por Unidades", cujos fundamentos se apresentam como objeto do presente artigo, que toma como finalidade discutir as unidades possíveis para a constituição de uma obutchénie dialética e desenvolvedora no contexto da educação escolar brasileira. Apresentada como síntese analítica de diversas intervenções didáticas realizadas em escolas públicas, tal proposição se abre para o diálogo e o debate que possam dar o sentido de movimento à ciência e à educação que se efetivam sob a base da superação e do desenvolvimento.

\section{Fundamentos de uma didática dialética e desenvolvedora: o cenário e a produção}

Uma perspectiva didática que proponha constituir-se por unidades fundamentase no materialismo histórico-dialético e tem seu marco epistemológico indubitavelmente na dialética, entendida como a ciência"das leis gerais do movimento e desenvolvimento da natureza, da sociedade humana e do pensamento." (Engels, 1951, p. 302). Considerando que a unidade dos contrários é uma das leis gerais da dialética, qualquer possibilidade de análise nesse sentido não pode negligenciar o conceito de unidade assentado na compreensão de síntese da luta entre contrários, na qual elementos, aspectos e/ou dimensões distintas produzem, pelo choque e confronto, a emergência do novo e se caracteriza, nuclearmente, pelo o que aqui se tem assumido como unidade.

Uma "Obutchénie por Unidades" presume fundar-se sob a base do que se pode designar como unidade primária, essencialmente, vinculada ao conceito de obutchénie. Dito de outra forma, para se pensar em uma "Obutchénie por Unidades" é preciso que se

2 A Intervenção Didático-Formativa é um tipo de pesquisa em Didática Desenvolvimental que tem sido produzido pelo esforço coletivo de um grupo de pesquisadores do Gepedi; e "[...] se constitui numa ação investigativoformativa, a partir da qual se faz, de forma intencional, uma intervenção no contexto educacional pela via da formação didática do professor; e, nesse processo, se constitui simultaneamente intervenção didática junto a classes de estudantes." (Longarezi, 2017b, p. 198). 
compreenda não apenas o sentido de unidade, tal como apresentado, mas também a própria compreensão de obutchénie, que, no sentido assumido pela perspectiva do Ensino Desenvolvimental russo, já se constitui pela unidade.

Transliteração da palavra russa "Обучение", obutchénie não encontra na língua portuguesa um código linguístico que represente seu conceito nessa dimensão de unidade que a perspectiva do Ensino Desenvovimental se assenta e que "[...] expressa justamente a unidade constitutiva da atividade docente que encerra tanto a atividade didática do professor quanto a atividade de autotransformação dos alunos" (Longarezi \& Puentes, 2017, p. 7, nota 1 da apresentação).

Na literatura russa obutchénie aparece como

a interação entre alunos e professores, a inter-relação entre a utchenia (aprendizagem) e os esforços profissionais do professor (se essa interação for compreendida com a noção de "atividade", então a obutchénie pode ser caracterizada como uma correlação entre atividade de estudo e atividade pedagógica) ${ }^{3}$. (Давыдов, 1996, p. 252, tradução das autoras 4 .

Assim sendo, obutchénie, como nos diz Davidov (1996), se "for compreendida com a noção de 'atividade" (Давыдов, 1996, p. 252), ou seja, se for considerada na perspectiva da Teoria da Atividade, "pode ser caracterizada como uma correlação entre atividade de estudo e atividade pedagógica" (Idem); não representada pela compreensão em separado de cada uma delas, como se fossem partes a serem somadas ou fundidas. No sentido dialético, unidade se constitui num novo elemento, que emerge enquanto síntese dos elementos anteriores e, nesse sentido, obutchénie na perspectiva da atividade, representa a unidade da atividade profissional docente e da atividade de autotransformação dos estudantes.

Entretanto, é preciso observar que, numa abordagem histórico-cultural da atividade, a aprendizagem, enquanto processo primário, é fundamental na obutchénie. Ainda nas palavras de Davidov (1996), na

[...] obutchénie, compreende-se como principal o processo de aprendizagem (ou assimilação), uma vez que os esforços dos professores são direcionados para a organização intencional desse processo primário. Apesar da assimilação e sua organização estarem inseparavelmente ligadas, historicamente têm sido criadas de \}

3 Обучение - это взаимодействие учащихся и учителей, взаимосвязь учения и профессиональных усилий учителя (если последнюю истолковывать с помощью понятия "деятель- ность", то обучение можно характеризовать как взаимосвязь учебной и педагогической еятельностей).

4 Todas as traduções das autoras, da obra de Давыдов (1996), apresentadas neste texto, foram realizadas a partir de tradução prévia do russo para o português, por Andrii Mishchenko, e fruto de aprofundamentos teóricoconceituais produzidos no interior do Gepedi. 
forma separadas as teorias da utchenia (aprendizagem) e do trabalho profissional do professor. ${ }^{5}$ (Давыдов, 1996, p. 252, tradução das autoras);

razão pela qual se tem construído compreensões dicotômicas entre as atividades de ensino e as de aprendizagem.

Na história da educação europeia e americana, havia basicamente duas teorias da utchenia (aprendizagem). Os fundamentos da primeira teoria foram formados por conceitos de associação, reflexo, estímulo-resposta (essa pode ser chamada de teoria do reflexo-associativo). A segunda é baseada nos conceitos de ação e tarefa (pode ser chamada de teoria da atividade). ${ }^{6}$ (Давыдов, 1996, p. 252, tradução das autoras).

Embasadas numa concepção tradicional de didática, e fundadas na cultura escolar essencialmente ocidental que nos caracteriza, as traduções de obutchénie para a língua portuguesa, mesmo quando referindo-se a uma abordagem histórico-cultural da atividade e do Ensino Desenvolvimental, vêm limitando-se a associá-la apenas ao "ensino", ou à "aprendizagem"; embora ainda sejam referenciadas pelas palavras "instrução" e/ou "educação". Nenhuma dessas opções a trata sob a ótica da unidade que sustenta esse conceito numa perspectiva da Didática Desenvolvimental da Atividade, na tradição da psicologia soviética russa.

Na literatura brasileira, há um esforço em conceituar a obutchénie, de modo a que se evidencie sua natureza distinta da compreensão "[...] convencional no Brasil de transmissão de conhecimento, [...] se refere na língua russa ao processo simultâneo de instrução, ensino, estudo, aprendizagem. [...], na qual estão implicados o ensino (o que o professor faz) e a aprendizagem (o que o aluno faz)" (Libâneo, 2014, p. 93).

Assim problematizada, a obutchénie, na perspectiva que estamos discutindo no âmbito da Didática Desenvolvimental da Atividade, não se restringe ao que culturalmente consideramos do campo do ensino, tampouco apenas da aprendizagem. Obutchénie não é tão somente uma coisa ou outra, "[...] refere-se a uma concepção-ação não cultural para nós, mas em que ambas dimensões e processos encontram-se em unidade." (Longarezi \& Puentes, 2017, p. 13); consiste síntese.

5 В обучении основным выступает процесс учения (или усвоения), поскольку усилия педагогов обращены на целенап- равленное управление именно этим первичным процессом. Несмотря на то что усвоение и управление им неразрывно связаны друг с другом, исторически были созданы раздельные теории учения и теории профессиональной работы учителя.

6 В истории европейско-американского образования сложи - лись две основные теории учения. В основе первой лежат понятия ассоциации, рефлекса, стимула-реакции (она может быть названа ассоциативно-рефлекторной теорией). Вторая опирается на понятия действия и задачи (ее можно назвать деятельностной теорией). 
[...] a obutchénie é um tipo especial de atividade docente que contempla, ao mesmo tempo, o trabalho ativo, colaborativo, intencional, comunicativo, motivado e emocional, tanto do professor quanto dos alunos, portanto do ensino e da aprendizagem, com vista ao desenvolvimento pleno das qualidades humanas dos sujeitos" (Longarezi \& Puentes, 2017, p. 12).

Demarcado o conceito fundante, no qual se origina a perspectiva propositiva de uma didática orientada por uma concepção de "Obutchénie por Unidades", faz-se manifesto a necessidade de que a obutchénie se realize enquanto processo de desenvolvimento integral de estudantes e professores. Portanto, da unidade primária obutchénie (ensinoaprendizagem) destaca-se a unidade obutchénie-desenvolvimento.

Orientada pela tese vigotskiana de que "a única boa obutchénie é a que se adianta ao desenvolvimento" (Vigotski, 2010, p. 114), na concepção de "Obutchénie por Unidades", a atividade pedagógica ${ }^{7}$ precisa ser organizada de modo a que se criem as condições para que o desenvolvimento das máximas possibilidades humanas seja impulsionado. Dito de outra maneira, uma "Obutchénie por Unidades" tem como princípio a unidade obutchénie-desenvolvimento, sem a qual a educação, numa perspectiva históricocultural, não assume sua natureza formativa e desenvolvedora.

O desenvolvimento implica novas formas de pensamento-ação-emoção e essas, por sua vez, são processos e produtos das sínteses que emergem das contradições e lutas a partir das quais são problematizados conhecimentos produzidos nas esferas da vivência ${ }^{8}$ e da ciência. Uma educação, nessa perspectiva, implica o desenvolvimento de conhecimentos, habilidades e comportamentos pela via da formação de um tipo especial de pensamento, denominado por Davidov como pensamento teórico.

O desenvolvimento de novas formas de pensamento não é um processo espontâneo; embora tenha por base as experiências cotidianas, ocorre mediado pelas teorias; portanto, na produção da práxis humana. Assim, esse processo depende de elementos novos a serem confrontados aos já estabelecidos no campo da vivência, depende da mediação teórica no processo colaborativo de educação. E essa não se sobrepõe à dimensão da vivência, se confronta a ela para que processos psíquicos, internos aos sujeitos, se constituam aprendizagem e, enquanto síntese dialética, se efetivem desenvolvimento.

A gênese do conhecimento está fundada na vivência dos inúmeros processos de

7 Entende-se por Atividade Pedagógica a "[...] unidade das atividades docente e discente [...]. Compreendemos [...] que a essência da atividade pedagógica é a obutchénie. Dessa maneira e pela sua natureza, a atividade pedagógica compreende a obutchénie como síntese e, portanto, tem o contexto escolar como espaço propício para se efetivar em processos educativos. [...]. Nesse enfoque teórico-metodológico, defendemos a obutchénie enquanto síntese expressa na essência da atividade pedagógica" (Longarezi \& Franco, 2017, p. 271). Pesquisadores brasileiros (Moura, 1996, 2001, 2017; Moura et al., 2010) têm tratado a atividade pedagógica enquanto unidade das ações docente e discente, pelo menos desde 1996.

8 Entendida no sentido vigotskiano de unidade entre o meio (aquilo que se vivencia) e as particularidades da personalidade (o modo como o sujeito vivencia). 
humanização presentes ao longo de sua existência. Contudo, mudanças qualitativas, desenvolvedoras de novas formas psíquicas, implicam processos de produção de sentidos pelo sujeito, mediado pelo confronto entre o "conhecido pela vivência" e o "conhecido pela ciência" (Longarezi, 2006; Longarezi, 2017b; Longarezi, Araujo \& Ferreira, 2007; Puentes \& Longarezi, 2013, 2017; Franco, 2015; Franco \& Longarezi, 2011).

A formação do conceito científico, uma importante finalidade da escola para a abordagem histórico-cultural da atividade, é um processo mental de produção de sentidos mediante o confronto das compreensões empíricas com as significações científicas produzidas pela humanidade; é, portanto, ato de pensamento. $\mathrm{O}$ desenvolvimento do pensamento teórico presume, nesse sentido, formar o conceito científico, quando entendido como ato mental, de forma mediada pelas problematizações oriundas das contradições inerentes às formas hipotéticas explicativas dos fenômenos e suas significações socialmente produzidas.

Destaca-se, no entanto, que os sentidos mobilizados na atividade humana de constituição da humanidade são vários e, portanto, essa não é uma atividade apenas cognitiva; o "[...] sujeito ativo, assumido em sua totalidade, mobiliza suas várias funções psicológicas, acionando e sendo acionado por seus diversos sentidos" (Longarezi, 2017b, p. 212). Dessa forma, o conteúdo em formação-desenvolvimento (transformação) se dirige ao homem como um todo, corresponde à sua formação integral, na qual dimensões intelectuais não existem separadas das dimensões dos afetos e emoções.

Entendido o sujeito e seus processos formativos enquanto totalidade, uma educação desenvolvimental e dialética, potencializadora do homem e da sociedade nas suas integralidades, precisa ser construída em meio às tensões que confrontam contradições, para que seja possível a formação-desenvolvimento de novas formas explicativo-emotivas da realidade. Assim sendo, motivos e sentidos podem emergir nesse processo, para que pensamento-ação-emoção sejam unidade constitutiva da vivência e da ciência, a compor os sentidos intra e intersubjetivos enquanto totalidade, na qual o sujeito se constitua "sócio-pessoal" e humanize-se, produzindo a si e a humanidade.

9 Sujeito sócio-pessoal entendido como unidade sujeito social-sujeito pessoal. Tal concepção de constituição humana se dá, primeiramente, porque não se compreende a existência do indivíduo descolada do social. Aqui se faz jus à compreensão fundamental vigotskiana da natureza sócio-histórica do homem. Na mesma medida, assume-se também que o social não é algo imprimido no indivíduo, como se o mesmo não criasse formas próprias de significação e produção do mundo. Dessa maneira, reconhece-se a dimensão da pessoalidade produzida pelo humano que também é o produtor do social. Nessa relação de unidade sujeito-sociedade, propõe-se a compreensão de sujeito social- sujeito pessoal ou sujeito sócio-pessoal. 


\section{Algumas unidades possíveis: uma perspectiva em cena/ encena}

Sob as bases da compreensão de uma obutchénie-desenvolvimento se fundamenta a proposição de uma "Obutchénie por Unidades". A partir da unidade ensinoaprendizagem (obutchénie) e da unidade obutchénie-desenvolvimento enunciamse outras (Longarezi, 2017b), aqui propostas como constituidoras de uma didática dialética e desenvolvedora: unidades conteúdo-forma, imitação-criação e rupturadesenvolvimento.

\section{Unidade conteúdo-forma}

A unidade conteúdo-forma, com foco especificamente nos processos didáticos, é a expressão plena da compreensão do conhecimento enquanto totalidade e da inexistência de produtos descolados dos processos nos quais se constituem. Com essa concepção, entende-se que os processos compõem os produtos e, assim, veem-se o lógico e o histórico do conteúdo encarnados em sua própria essência. Tal abordagem se constitui o núcleo da unidade conteúdo-forma.

O "lógico", que progressivamente se vai formando no processo de evolução histórica do conhecimento, é também o comum que se relaciona tanto a evolução histórica do conhecimento como o processo do estudo entre si. E é aí que se assenta a sua unidade. $\mathrm{Na}$ evolução histórica do conhecimento percorreu-se um determinado caminho para elaborar este "lógico", cujo caminho reflecte [sic] a lógica do objeto [sic] de acordo com as condições concretas da evolução histórica (Rubinstein, 1973, p. 135).

Segundo Kopnin (1978), a história do desenvolvimento do objeto cria os elementos imprescindíveis constitutivos de sua essência e, nesse sentido, os "fixa" em suas formas de abstração; em seu conceito. Desse modo, a história do desenvolvimento do objeto constitui a teoria do objeto.

O lógico, por sua vez, se expressa na "[...] essência do objeto e da história do seu desenvolvimento no sistema de abstrações" (Kopnin, 1978, p. 183), é a apropriação do histórico pelo pensamento humano. Por isso, "o lógico é o histórico libertado das casualidades que o perturbam" (Ibid., p. 184).

Dessa forma, o conceito como atividade mental, síntese abstrata do objeto, e, no caso do conceito científico, como síntese de sua abstração teórica, carrega em sua essência o lógico e o histórico do conteúdo científico.

No sentido da "atividade pedagógica", não cabe à obutchénie reprodução pari passo da história do conhecimento, isso seria reconstruir a teoria do conceito. A perspectiva 
de uma didática desenvolvimental está alicerçada na organização de uma obutchénie, de tal modo que o lógico-histórico seja objeto da "atividade pedagógica" pela via do estudo nuclear do conceito existente no conteúdo escolar, sem que se faça necessário a reconstrução do processo de elaboração do conceito, sem que seja novamente percorrido o percurso científico da produção do conceito. $O$ desafio reside, pois, em encontrar no conceitual sua essência, na qual o lógico e o histórico estejam encarnados. E, nesse sentido, o lógico-histórico seria tratado pela via da essência do conceito, na ascensão do abstrato ao concreto.

A unidade conteúdo-forma sinaliza para a necessidade da apreensão dos modos investigativos nos quais a ciência da disciplina produz seus conteúdos, de maneira em que a essência, enquanto o nuclear, seja o objeto do ensino, pela via dos nexos conceituais a ela inerentes, permitindo a apropriação do lógico-histórico do conceito, nuclear do conhecimento científico; num movimento do abstrato ao concreto.

Trata-se, portanto, de unir no ensino a lógica do processo de investigação com os produtos da investigação. Ou seja, o acesso aos conteúdos, a aquisição de conceitos científicos, precisa [...] os modos de pensar e investigar da ciência ensinada. Não basta aprender o que aconteceu na história, é preciso pensar historicamente. Pensar matematicamente sobre matemática, biologicamente sobre biologia, linguisticamente sobre português, e assim por diante. (Libâneo, 2008, 13).

Nesse sentido, o epistemológico do conteúdo contém o epistemológico da ciência na qual ele se insere. "Aprender o conteúdo é, então, interiorizar os modos de pensar, de raciocinar e de investigar próprios da ciência ensinada" (Libâneo, 2008, p.15). Tratado o processo de obutchénie-desenvolvimento na perspectiva da unidade conteúdo-forma (Longarezi, 2017b), implica compreender que a aprendizagem teórica

[...] consiste em captar o princípio geral, as relações internas de um conteúdo, o desenvolvimento do conteúdo. É aprender a fazer abstrações para formar uma célula dos conceitos-chave, para fazer generalizações conceituais e aplicá-las a problemas específicos. Para isso: captar o caminho já percorrido pelo pensamento científico como forma de interiorização de conceitos e aquisição de métodos e estratégias cognitivas. (Libâneo, 2008, 14).

A unidade conteúdo-forma implica, portanto, a organização didática da obutchénie, pela via da formação do conceito científico, com o estudo do lógico-histórico dos conceitos, encontrando nos nexos conceituais caminho de apropriação do nuclear do conceito, desenvolvendo um pensamento epistemológico da ciência que se estuda; não se apropriando apenas do produto da ciência, mas aprendendo a pensar pela lógica da própria ciência, desenvolvendo o pensamento teórico-científico nas várias áreas do conhecimento. 


\section{Unidade imitação-criação}

[...] a imitação, entendida em sentido amplo, é a forma principal em que a obutchénie influência o desenvolvimento. (Vigotski, 2007, p. 357, tradução das autoras10).

Pode-se considerar estabelecido na moderna psicologia da imitação que a criança pode imitar apenas o que está na zona de suas próprias possibilidades intelectuais.

(ibid., p. 354, tradução das autoras).

Quando Vigotski revoluciona a relação obutchénie-desenvolvimento, demonstrando por inúmeras vias experimentais como a obutchénie bem organizada pode promover o desenvolvimento, o faz sob a tese de que a todo e qualquer nível real de desenvolvimento se tem um nível possível a desenvolver quando da colaboração do "outro mais experiente" na "atividade pedagógica". O processo de imitação depende do estado de desenvolvimento da criança, não fosse assim, diz Vigotski (2007, p. 355, tradução das autoras), "se pudesse imitar tudo o que quisesse, independentemente do estado do seu desenvolvimento, ambas as crianças teriam resolvido com idêntica facilidade todos os testes calculados para todas as idades infantis". Nesse intervalo, entre o real e a possibilidade, reside uma zona de desenvolvimento possível (ZDP). $\mathrm{Na}$ perspectiva proposta por Vigotski, é orientada pelas possibilidades a serem desenvolvidas (ZDP) que uma boa obutchénie pode ser organizada para que o nível possível torne-se real, criando as condições pedagógicas para o desenvolvimento.

Para explicar esse fato, constatado pela investigação, podemos recorrer à conhecida e indiscutível tese que diz que em colaboração, sob a orientação e ajuda de alguém, a criança sempre poderá conseguir mais e resolver tarefas mais difíceis que se o fizesse de forma independente. (Vigotski, 2007, p. 354, tradução das autoras).

Dissemos que, em cooperação, uma criança sempre pode fazer mais do que sozinha. Mas devemos acrescentar: não infinitamente mais, mas apenas dentro de certos limites estritamente definidos pelo estado de seu desenvolvimento e suas possibilidades intelectuais. (ibid., p. 355, tradução das autoras).

$\mathrm{Na}$ abordagem dada pelo autor a esse campo conceitual da obutchénie e do desenvolvimento, a imitação se processa na ZDP e é fundamental na "atividade pedagógica". Para Vigotski (2006, p. 268) "tudo quanto uma criança não é capaz de

10 As traduções das citações de Vigotski (2007) são traduções comparadas. Foram realizadas pelas autoras a partir da edição argentina de "Pensamiento y habla", confrontadas com o original em russo "Исследование развития научных понятий в детском возраст. Опыт построения рабочей гипотезы" (Estudo do desenvolvimento dos conceitos científicos na infância. Experiência na construção de uma hipótese de trabalho), de Л.C. Выготский (L. S. Vigotski), 1999. 
realizar por si mesma, mas pode aprender sob a direção ou a colaboração do adulto, ou com a ajuda de perguntas orientadoras, incluímos na área da imitação", portanto, tudo que não consegue realizar sozinha, pode fazê-lo em colaboração com o outro, na zona de desenvolvimento possível.

[...] na escola a criança não aprende o que sabe fazer sozinha, mas o que ainda não conhece e lhe vem a ser acessível em colaboração com o professor e sob sua orientação. O fundamental na obutchénie é justamente o fato de que a criança aprende o novo. Por isso, a zona de desenvolvimento possível, que determina o âmbito dos passos que estão ao alcance da criança, é o aspecto mais decisivo na relação da obutchénie com o desenvolvimento. (Vigotski, 2007, p. 357, tradução das autoras).

Nota-se a relevância da imitação no processo de obutchénie-desenvolvimento que, nessa perspectiva, não ocorre sem a cooperação, a orientação do "outro mais experiente"; aliás, se materializa na colaboração. É essa dimensão colaborativa que resguarda a imitação, numa abordagem vigotskiana, certas especificidades.

Ao falar de imitação, não nos referimos a uma imitação mecânica, automática, sem sentido, mas sim a uma imitação racional, baseada na compreensão da operação intelectual que se imita. Quer dizer, de um lado restringimos o significado do termo ao referirmos unicamente à esfera de operações mais ou menos relacionada com a atividade racional da criança; e por outro lado, ampliamos o significado do termo, empregando a palavra "imitação" aplicando a toda atividade que a criança não realiza por si só, mas sim em colaboração com um adulto ou outras crianças (Vigotski, 2006, p. 268).

Dessa maneira, a tese da ZDP envolve imitação e colaboração, por isso, não como uma reprodução mecânica de ato ou operação. Numa perspectiva marxista e vigotskiana, todo ato imitativo se produz sob a base da subjetividade de quem imita, e, portanto, se assenta no "sujeito sócio-pessoal" que reinventa; reelabora de maneira criativa impressões e vivências.

[...] elementos da experiência anterior nunca se reproduzem, na brincadeira, exatamente como ocorreram na realidade. A brincadeira da criança não é uma simples recordação do que vivenciou, mas uma reelaboração criativa de impressões vivenciadas. É uma combinação dessas impressões e, baseada nelas, a construção de uma realidade nova que responde às aspirações e aos anseios da criança. Assim como na brincadeira, o ímpeto da criança para criar é a imaginação em atividade (Vigotski, 2009, p. 17).

Por essa perspectiva, no intervalo entre o nível de desenvolvimento real e o possível, a imitação se apresenta como fundamental, pela via da colaboração. "A obutchénie é possível onde existe a possibilidade de imitar" (Vigotski, 2007, p. 358, tradução das autoras). Embora, no sentido vigotskiano, a ênfase esteja no papel da imitação em processos de obutchénie, é preciso enfatizar que a imitação não se constitui, 
como apontado, em um ato mecânico-reprodutivo: "Ao imitar, o indivíduo nunca faz uma mera cópia do outro, estando em constante processo de criação." (Fernandes, 2007 , p. 11). Compreende-se, pois, a necessidade de que a imitação no processo de obutchénie-desenvolvimento seja concebida em unidade com os processos criativos produzidos por cada sujeito e, assim, propõe-se a síntese imitação-criação. Na acepção vigotiskiana:

Toda atividade do homem que tem como resultado a criação de novas imagens ou ações, e não a reprodução de impressões ou ações anteriores da sua experiência pertence a esse segundo gênero de comportamento criador ou combinatório. $O$ cérebro não é apenas o órgão que conserva e reproduz nossa experiência anterior, mas também o que combina e reelabora, de forma criadora, elementos da experiência anterior, erigindo novas situações e novo comportamento. Se a atividade do homem se restringisse à mera reprodução do velho, ele seria um ser voltado somente para o passado, adaptando-se ao futuro apenas na medida em que este reproduzisse aquele. É exatamente a atividade criadora que faz do homem um ser que se volta para o futuro, erigindo-o e modificando o seu presente (Vigotski, 2009, p. 13-14).

Numa abordagem dialética a imitação-criação se constitui síntese e se expressa como processo de superação; não é um novo "puro", sem traços do "antigo imitado", porém, surge dos processos de confrontos entre elementos distintos e contraditórios; é voltada para o futuro, para o desenvolvimento. Assim, essa unidade se constitui pela imitação no processo de obutchénie-desenvolvimento, mas não como ato restrito a um impulso reprodutor; como processo criativo, de produção de sentidos e, portanto, como síntese do movimento de constituição humana.

Nessa perspectiva, então, imitação e criação não existem enquanto processos isolados. Da mesma maneira em que não se pode criar sem a oportunidade de imitar (com a colaboração) na zona de possibilidade; não existe uma imitação que seja "pura", a partir da qual não se crie.

Em condições de uma obutchénie desenvolvedora, a unidade imitação-criação é um elemento fundamental para processos de desenvolvimento como movimentos dialéticos produzidos enquanto sínteses; expresso de variadas formas, considerando as subjetividades de cada sujeito em particular. Em alguns estudos (Dias de Sousa, 2016; Dias de Sousa \& Longarezi, 2017, 2018; Longarezi, 2017b) evidencia-se a unidade imitação-criação como nuclear em processos de formação-desenvolvimento em contexto de escolas públicas brasileiras. Há dados que indicam como no processo de imitação-criação se revelam

[...] elementos que explicam mecanismos de produção da psiquê humana, e, por conseguinte, da produção de cada história em particular, pois a cultura e, especialmente, os bens culturais produzidos por meio da ciência são apropriados e reelaborados por meio das sínteses de cada sujeito em especial [...]. Esse processo não é passivo e muito menos, meramente, reprodutivo, desde que o sujeito envolvido construa, em 
colaboração, instrumentos que lhe subsidiem a ter uma atitude consciente e intencional diante dos encaminhamentos teórico-práticos. A colaboração, portanto, encaminha o sujeito para a autonomia, ou seja, para a ampliação de condições de ele se autogovernar e tomar decisões pautadas nas sínteses teórico-práticas que formula, ao longo de um processo que dura toda a existência, em elaborações que podem ser cada vez mais sofisticadas e criativas. Imitar e criar, portanto, são faces antagônicas que se complementam [...]. De um lado a imitação fornece as referências, os modelos, as imagens e, de outro, tomando como base a luta que se estabelece dentro do homem para que ele se produza, a criação apresenta a síntese, a novidade, a plasticidade de cada indivíduo em especial numa dada realidade (Dias de Sousa, 2016, ps. 249-250).

Nesse sentido, o trabalho colaborativo na zona de desenvolvimento possível do estudante é princípio e prática para a materialidade da unidade imitação-criação em uma "obutchénie" que se pretenda desenvolvedora, constituída com base numa concepção "por unidades".

\section{Unidade ruptura-desenvolvimento.}

A unidade ruptura-desenvolvimento compõe, junto às demais, a "atividade pedagógica" intencionalmente realizada para a formação e o desenvolvimento humano (Longarezi, 2017b). Essa unidade é a expressão de que o desenvolvimento só se realiza enquanto processo de ruptura, de síntese, enquanto revelação de superação. Assim, o cerne da unidade ruptura-desenvolvimento encontra-se na lei da unidade dos contrários, que representa a essência da lógica dialética; entendida a dialética como doutrina da unidade dos contrários (Kopnin, 1978).

Indissociavelmente ligada, portanto, à lógica do movimento de luta dos contrários, a unidade ruptura-desenvolvimento se expressa a partir de confrontos e superações; e "a chave para a transformação está na ruptura possível, gerada no embate entre as forças contraditórias colocadas em confronto" (Longarezi, 2017b, p. 211).

Transformações que representem a emergência do novo, com superações, presumem mudanças na essência, mudanças de qualidade, que têm sua marca enunciativa na ruptura.

[...] a ruptura pode ser considerada o ápice do processo de luta e confronto entre os diferentes e contraditórios tipos de conhecimentos; a superação, caracterizando o ponto alto da mudança qualitativa, provocado pelo enfrentamento das contradições inerentes aos fenômenos e processos envolvidos no transcurso da formação-desenvolvimento [...]. A ruptura se constitui, pois, em processo fundamental na passagem da quantidade à qualidade no movimento de desenvolvimento do pensamento-ação [...]. (Longarezi, 2017b, p. 213) 
Numa concepção de "Obutchénie por Unidades", a transformação (rupturadesenvolvimento) se dá, portanto, no processo de confronto entre diferentes tipos de conhecimentos, o que implica luta entre contrários. É, então, na dialética que reside a essência do movimento que produz mudanças qualitativas essenciais nas formas de pensamento, propulsoras de novas formações psíquicas, desenvolvimento; o que dá à obutchénie os elementos para que se constitua enquanto processo dialético e desenvolvimental.

Nesse movimento, a ruptura é um processo fundamental para que ocorra a emergência de novas funções psíquicas. O novo representa um estágio de superação, produzido pela síntese entre diferentes e contraditórias maneiras explicativas do fenômeno "resguarda características já constituídas, mas reestruturadas. Por isso, emerge sob a égide da transformação (Longarezi, 2006), da unidade ruptura-desenvolvimento" (Longarezi, 2017b, 214); o que caracteriza a mudança de qualidade como resultado do movimento de luta e produção de sínteses; dando materialidade a essa unidade.

No sentido didático isso se efetiva na "atividade pedagógica", tal como compreendida pela psicologia histórico-cultural. Uma abordagem dialética que se enfatiza a partir de uma concepção de "Obutchénie por Unidades" implica assumir que um novo modo de pensamento sobre os fenômenos é processo e produto de confrontos entre os modos explicativos espontâneos e científicos; é síntese.

Nessa perspectiva, a tomada de consciência, tal como empreendida por Vigotski (2007), configura-se processo fundamental na formação de conceitos, no desenvolvimento do pensamento por conceitos. [...] a tomada de consciência está baseada na generalização dos próprios processos psíquicos, o que conduz ao seu domínio. Nesse processo, o papel decisivo é desempenhado principalmente pela obutchénie. [...] a tomada de consciência ingressa pela porta dos conceitos científicos (Vigotski, 2007, p. 315, tradução das autoras).

Há pesquisas (Germanos, 2016; Germanos et al., 2014; Germanos et al., 2015; Souza, 2016; Ferola, 2016) que têm revelado em processos de intervenção didático-formativas como a tomada de consciência é impulsionada pelas contradições, que assumem papel fundamental para a emergência de superações, propulsoras do desenvolvimento (Germanos, 2016). A organização didática da obutchénie, na perspectiva da unidade ruptura-desenvolvimento, precisa, portanto, "[...] promover situações que permitam a emergência de contradições (compreendidas como força motriz de mudança)" (Germanos, 2016, p. 235).

A tomada de consciência consiste na transformação da essência do pensamento, expressa pela mudança qualitativa que representa o modo novo de pensamento enquanto síntese da atividade mental. Entendida como sistematização de conceitos e generalização, a tomada de consciência se configura como ato mental, no qual estão envolvidas várias operações mentais, corresponde à generalização abstrata e a principal forma de pensamento se expressa como síntese (Nuñez, 2009). 
A unidade ruptura-desenvolvimento tem suas bases, portanto, no movimento possível, fundado nas leis da dialética, de transformação do pensamento pela obutchénie que provoque o confronto entre diferentes formas de conhecimento e seja propulsor, não apenas de mudanças quantitativas, mas de rupturas que permitam de fato mudanças na essência, que gere desenvolvimento. Essa é uma das teses centrais da Didática Desenvolvimental, a da obutchénie que impulsiona o desenvolvimento, orientada pela compreensão de formação e desenvolvimento humanos defendidos pela psicologia soviética da época. (Longarezi, 2017b, p. 215).

Dessa forma, a tomada de consciência é assumida como "chave" para a transformação. Ruptura-desenvolvimento constitui-se, pois, uma unidade que revela o processo de formação e desenvolvimento humano na sua integralidade pela via da tomada de consciência, aqui entendida como processo que, indubitavelmente, "[...] implica em motivações mediadas por emoções, sentidos e significados [...]." (Carvalho et al., 2010, p. 18); compreendendo ruptura-desenvolvimento (cognitivo-afetivo) do homem na sua totalidade.

A transformação, na unidade "sujeito sócio-pessoal", não está, portanto, limitada ao desenvolvimento cognitivo; uma vez que não existe um processo racional de desenvolvimento que não o seja igualmente processo emocional. $O$ homem, em sua totalidade, imenso e emergente de contradições não o é parte razão, parte emoção; encontra-se humano em sua plenitude, portanto, racional e emocional.

\section{Obutchénie-desenvolvimento: motivos para um novo ensejo.}

Obutchénie-desenvolvimento é motivo e finalidade, processo e produto, necessidade e sentido da "atividade pedagógica" numa perspectiva desenvolvimental. Nela temos encarnadas duas unidades fundamentais para a constituição de uma didática dialética e desenvolvedora que se constitua "por" "e partir de" contradições: a obutchénie enquanto unidade "ensino-aprendizagem" e a unidade "obutchéniedesenvolvimento".

Os caminhos percorridos na construção dessa compreensão levaram à sistematização das unidades conteúdo-forma, imitação-criação, ruptura-desenvolvimento, que se constituem nos fundamentos para uma concepção de "Obutchénie por Unidades".

Em tal perspectiva o estudo pelo lógico-histórico do conteúdo, num movimento de ascensão do abstrato ao concreto, delineia conteúdo-forma como uma das unidades possíveis. Essa é uma atividade que demanda processos colaborativos na zona de possibilidade dos sujeitos, pela via da unidade imitação-criação, outra importante condição para uma obutchénie desenvolvedora de estudantes e professores. 
Contudo, assumido o desenvolvimento numa perspectiva dialética da obutchénie e da formação-constituição humana, ele só se materializa quando ocorre uma transformação na essência do pensamento-ação-emoção e se dê sob a base da ruptura, estabelecendo-se a partir da formação-desenvolvimento do "novo" (produzido como síntese da luta entre as contradições inerentes aos fenômenos concretos da vida na condição humana a que se está imerso); assim se constitui mais uma unidade fundamental para uma obutchénie-desenvolvimento na perspectiva histórico-cultural: a ruptura-desenvolvimento. Em todas elas revelam-se as contradições e lutas que se constituem nas forças propulsoras do desenvolvimento e da superação no sentido de uma "Obutchénie por Unidades".

Essa concepção, produzida a partir de um conjunto de investigações realizadas no interior de um grupo de pesquisa no Brasil (Souza, 2016; Souza \& Longarezi, 2017; Ferola, 2016; Franco, 2015; Franco \& Longarezi, 2011; Longarezi \& Franco, 2015, 2016, 2017; Franco, Longarezi \& Marco, 2017, 2018; Dias de Souza, 2016; Dias de Souza \& Longarezi, 2017, 2018; Germanos, 2016), revela o esforço que se tem produzido no sentido de contribuir para a discussão de uma perspectiva didática que seja mobilizadora de estudantes e professores, com a finalidade da formação e do desenvolvimento integral dos sujeitos. Existem vários outros grupos de pesquisa, no Brasil, no campo da didática desenvolvimental e da teoria histórico-cultural, que têm empreendido esforços nesse sentido. O diálogo e as parcerias entre tais movimentos podem ser um importante caminho para a construção de uma abordagem de obutchénie no país que tenha fundamentos, princípios, ações e práticas capazes de mobilizar a escola pública brasileira e auxiliem na consolidação de uma educação desenvolvedora do homem e da sociedade.

A proposição de uma "Obutchénie por Unidades" traz à tona uma problemática a partir da qual se espera contribuir para que outros elementos se constituam motivos para um novo ensejo e fomentem o debate e a consolidação de uma educação e uma sociedade mais humanizadoras. 


\section{Referências}

Carvalho, M.A. A.S., Araújo, S. M. M.,Ximenes, V.M., Pascual, J.G. (2010). A formação do conceito de consciência em Vygotsky e suas contribuições à psicologia. Arquivos Brasileiros de Psicologia, 62(3), 13-22. Recuperado em 27 de agosto, 2018, de http:// pepsic.bvsalud.org/pdf/arbp/v62n3/V62n3a03.pdf

Coelho, G. M. de S. (2016). A felicidade em ser docente: vozes que ressoam no campus Amíl Ferreira Sobral [projeto de pesquisa de mestrado]. Uberlândia: Programa de Pós-Graduação em Educação. Universidade Federal de Uberlândia.

Dias de Sousa, W. D. (2016). Processos de imitação-criação como constituidores da práxis pedagógica. Tese de Doutorado, Universidade Federal de Uberlândia, Uberlândia/MG.

Dias de Sousa, W. D. \& Longarezi, A. M. (2017). Imitation-creation processes in teachers' education. Научный результат. Педагогика и психология образования (Resultados Científicos: Pedagogia e Psicologia da Educação), 3(3), 10-15. Recuperado em 27 de agosto, 2018 de https://cyberleninka.ru/article/n/ imitation-creation-processes-in-teachers-education

Dias de Sousa, W. D \& Longarezi, A. M. (2018). Imitação-criação no processo de formação para o desenvolvimento profissional docente. Praxis Educativa, 13(1), 443-462. Recuperado em 31 de janeiro, 2018 de http://www.revistas2.uepg.br/ index.php/praxiseducativa/article/view/10308/6255

Engels, F. (2015). Anti-Dühring, São Paulo: Boitempo Editorial.

Fernandes, V. L. P. (2007). Uma leitura sócio-histórica da imitação no processo de ensino e aprendizagem. Anais da 30ª Reunião Anual da ANPed, Caxambu-MG.

Ferola, B. de C. (2016). Contribuições para a didática desenvolvimental no ensino médio: ações didáticas para a formação de conceitos científicos em biologia. Monografia, Universidade Federal de Uberlândia, Uberlândia/MG.

Ferola, B. de C. (2017). Sistema zankoviano de ensino e suas implicações para uma didática na perspectiva histórico-cultural no contexto educacional brasileiro [projeto de pesquisa de mestrado]. Uberlândia: Programa de Pós-Graduação em Educação. Universidade Federal de Uberlândia.

Ferreira, I. M. (2017). Aprendizagem e desenvolvimento infantil na perspectiva da didática desenvolvimental [projeto de pesquisa de doutorado]. Uberlândia: Programa de Pós-Graduação em Educação. Universidade Federal de Uberlândia. 
Franco, P. J. L. O desenvolvimento de motivos formadores de sentido no contexto das atividades de ensino e estudo na escola pública brasileira. (2015). Tese de doutorado. Universidade Federal de Uberlândia, Uberlândia/MG.

Franco, P. J. L. \& Longarezi, A. M. (2011). Elementos constituintes e constituidores da formação continuada de professores: contribuições da teoria da atividade. Revista Educação e Filosofia, 25(50), 557-582.

Franco, P. J. L., Longarezi, A. M., Marco, F. F. de. (2017). Motives in brazilian school education according to the cultural historical perspective and the developmental education approach Научный результат. Педагогика и психология образования (Resultados Científicos: Pedagogia e Psicologia da Educação), 3(3), 550-559. Recuperado em 27 de agosto, 2018 de https://cyberleninka.ru/article/n/motivesin-brazilian-school-education-according-to-the-cultural-historical-perspectiveand-the-developmental-education-approach

Franco, P.J. L., Longarezi, A. M., Marco, F. Fiorezi de. (2018). Fundamentos teórico-metodológicos de ações didático-formativas no contexto da docência em matemática. In: Cyrino, M. C. de C.T. Temáticas emergentes de pesquisas sobre a formação de professores que ensinam matemática: desafios e perspectivas. (E-book). Brasília: SBEM, 2018. p. 177-193. (Coleção SBEM ; 10) 3,1.

Gali , M. L. C. (2018). O experimento didático na literatura em língua portuguesa e espanhola [projeto de iniciação científica]. CNPq/UFU.

Germanos, E. (2016). Contradições como força de mudança: o processo de formação continuada de professores do ensino médio enquanto potencializador da práxis transformadora à luz da teoria histórico-cultural. (2016). Tese de doutorado. Universidade Federal de Uberlândia, Uberlândia/MG.

Germanos, E., Souza, L. M. A., Ferola, B. C., Costa, V. P. C. (2014). Formação para docência e as contribuições da teoria histórico-cultural no contexto brasileiro. In: Atas do Congresso Formação e trabalho docente na sociedade da aprendizagemInternational Study Association on Teachers and Teaching (ISATT), Braga, Portugal.

Germanos, E., Souza, L. M., Costa, V. P., Ferola, B. C., Souza, C. F. (2015). Aprendizagem e desenvolvimento docente em movimento: experiências de uma formação continuada no contexto da teoria históricocultural. Anais do XII Congresso Nacional de Educação-EDUCERE, Curitiba, Paraná.

Jesus, S. F. (2018). Ensino desenvolvimental: uma intervenção didático-formativa junto a supervisores de ensino [projeto de pesquisa de doutorado]. Uberlândia: Programa de Pós-Graduação em Educação. Universidade Federal de Uberlândia. 
Kopnin, P. V. (1978). A dialética como lógica e teoria do conhecimento. Rio de Janeiro: Civilização Brasileira.

Libâneo, J. C. (2008). Didática e epistemologia: para além do embate entre a didática e as didáticas específicas. In: Veiga, I. P.A. \& D’Ávila, C. (Orgs.). Profissão docente: novos sentidos, novas perspectivas. Campinas: Papirus Editora.

Libâneo, J. C. (2014). Didática e docência: formação e trabalho de professores da educação básica. In: Cruz, G. B. et. alii (orgs.). Ensino de didática: entre recorrentes e urgentes questões. Rio de Janeiro: FAPERJ/Quartet.

Longarezi, A. M. (2006). Práxis e formação de professores: aspectos relevantes para se pensar uma epistemologia da formação docente. Educação e Linguagem (Vol 1, N. 1, pp.157-175). São Paulo, São Bernardo do Campo: UMESP.

Longarezi , A. M. (2012). Didática desenvolvimental no contexto da escola pública brasileira: modos e condições para um ensino que promova o desenvolvimento [projeto de pesquisa]. Brasília, DF: CAPES, Programa Observatório da Educação, Edital 049/2012.

Longarezi , A. M. (2014). Didática desenvolvimental: intervenções pedagógicoformativas desenvolvedoras de estudantes do ensino fundamental, médio e superior [projeto de pesquisa]. Brasília, CNPq, Conselho Nacional de Desenvolvimento Científico e Tecnológico.

Longarezi , A. M. (2017a). Intervenção didático-formativa: uma proposta metodológica para pesquisas-formação numa perspectiva desenvolvimental [projeto de pesquisa]. Brasília, CNPq, Conselho Nacional de Desenvolvimento Científico e Tecnológico, São Paulo: USP. Pós-doutorado.

Longarezi, A. M. (2017b). Para uma didática desenvolvimental e dialética da formação-desenvolvimento do professor e do estudante no contexto da educação pública brasileira. Obuchenie. Revista de Didática e Psicologia Pedagógica. 1(1), 187-230. Recuperado em 06 de julho, 2018 de file:///C:/Users/Andrea/ Downloads/39912-169768-1-PB\%20(18).pdf

Longarezi, A. M., Araujo, E. S., Ferreira, S. (2007). A psicologia histórico-cultural na formação do profissional docente. Série Estudos, 23, 65-78. Recuperado em 27 de agosto, 2018 de http://www.serie-estudos.ucdb.br/index.php/serie-estudos/ article/view/262

Longarezi, A. M \& Franco, P. J. L.. (2015). А.Н. Леонтьев: жизнь и деятельность психолога. Dubna Psychological Journal, n.1. 
Longarezi I, A. M \& Franco, P. J. L. (2016). A formação-desenvolvimento do pensamento teórico na perspectiva histórico-cultural da atividade. Revista Educativa, 19(2), 449-473. Recuperado em 27 de agosto, 2018 de file:///C:/Users/ Usuario/Downloads/5406-16317-1-PB.pdf

Longarezi, A. M. \& Franco, P. J.L.(2017). Atividade pedagógica na unidade significado social-sentido pessoal. In: Longarezi, A. M. \& Puentes, R. V. (Orgs.). Fundamentos psicológicos e didáticos do Ensino Desenvolvimental. Uberlândia: EDUFU.

Longarezi, A. M. \& Puentes, R. V. (2017). Fundamentos psicológico-didáticos para um ensino na perspectiva histórico-cultural: a unidade dialética obutchéniedesenvolvimento. In: Longarezi, A. M. \& Puentes, R. V. (Orgs.). Fundamentos psicológicos e didáticos do Ensino Desenvolvimental. Uberlândia: Edufu.

Marra, J. B. J. (2017). Formação de formadores de professores para e por um Ensino Desenvolvimental de línguas: uma intervenção didático-formativa na educação superior em Moçambique [relatório de qualificação de doutorado]. 147f. Programa de PósGraduação em Educação. Universidade Federal de Uberlândia, MG.

Moura, M. O. de. (1996). A Atividade de ensino como unidade formadora. Bolema, 12, 29-43. Rio Claro: UNESP.

Moura, M. O. de. (2001). Atividade de ensino como ação formadora. In: Castro, A.D.; Carvalho, A.M.P. de (org). Ensinar a ensinar - didática para a escola fundamental e média. São Paulo: Pioneira Thomson Learning.

Moura, M. O. de (Org.) (2017). Educação escolar e pesquisa na teoria histórico-cultural. São Paulo: Edições Loyola.

Moura, M. O. de., Araujo, E. S., Souza, F. D. de, Panossian, M. L., Moretti, V. D. (2010). Atividade orientadora de ensino como unidade entre ensino e aprendizagem. In: Moura, M. O. de. (Org.). A atividade pedagógica na teoria histórico-cultural. Brasília: Liber Livro.

Núñez, I. B. (2009). Vygostsky, Leontiev e Galperin: formação de conceitos e princípios didáticos. Brasília: Liber Livro.

Puentes, R. V. \& Longarezi, A. M. (2013). Escola e didática desenvolvimental: seu campo conceitual na tradição da teoria histórico-cultural. Educação em Revista, 29(1), 247-271. Recuperado em 05 de fevereiro, 2013 em: http://www.scielo.br/pdf/ edur/v29n1/aop_224.pdf

Puentes, R. V. \& Longarezi, A. M. (2017). A didática desenvolvimental: seu campo conceitual na tradição da psicologia histórico-cultural da atividade. In: Longarezi, 
A. M.; Puentes, R. V. Fundamentos psicológicos e didáticos do Ensino Desenvolvimental. Uberlândia: EDUFU.

Rubinstein, S.L. (1973). Princípios da psicologia geral. Lisboa: Editorial Estampa.

Vigotski , L. S. (1991). Obras escogidas, tomo I. Madri: Visor e MEC.

Vigotski, L. S. El problema de la edad. (2006) In: Vygotski, L. S. Problemas de la psicología infantil. Obras Escogidas. (L. Kuper, Trad.). 2 ed. Madrid: Visor.

Vigotski, L. S. (2007). Pensamiento y habla. (A. A. González, Trad.). Buenos Aires: Colihue.

Vigotski, L. S. (2009). Imaginação e criação na Infância. (Z. Preste, Trad.). São Paulo: Ática.

Vigotski, L. S. (2010). Aprendizagem e desenvolvimento intelectual na idade escolar. In: Vigotski, L. S., Luria, A. R., Leontiev, A. N. Linguagem, desenvolvimento e aprendizagem. $10^{\mathrm{a}}$ edição. São Paulo: Î́cone.

Souza, L. M. de A. (2016). A sociologia no ensino médio: princípios e ações didáticas orientadoras de um ensino que possibilite o desenvolvimento de adolescentes em uma perspectiva histórico-cultural. Dissertação de Mestrado. Universidade Federal de Uberlândia, Uberlândia/MG.

Souza, L. M. de A. (2017). Princípios didáticos para um ensino desenvolvimental da atividade [projeto de pesquisa de doutorado]. Uberlândia: Programa de PósGraduação em Educação. Universidade Federal de Uberlândia.

Souza, L. M. A.; Longarezi, A. M.. (2017). Principles and didactic activities of developmental education in the transitional stage. Гуманитарно-педагогические исследования. In: Humanitarian and pedagogical Research, 1(2), 16-21. Recuperado em 27 de agosto, 2018 de https://cyberleninka.ru/article/n/didactic-principlesand-methods-of-developmental-training-at-a-transitional-age

Давыдов, B.B. (Davidov, V.V.) (1996).Теория развивающего обучения. (Teoria do Ensino Desenvolvimental. Moscó: ИНTOP, 544c.

Выготский, Л.C. (Vigotski, L.S.) (1999). Исследование развития научных понятий в детском возраст. Опыт построения рабочей гипотезы (Estudo do desenvolvimento dos conceitos científicos na infancia. Experiência na construção de uma hipótese de trabalho). Выготский, Л.C. (Vigotski, L.S.) Мышление и речь (Pensamento e Fala) Изд. 5, испр. - Издательство "Лабиринт", М., рр.172274. 